\title{
Active Principles which are Important to Human Health Obtained from Ceramium Rubrum - Seaweed in the Black Sea
}

\author{
Rodica Sîrbu \\ Ticuţa Negreanu-Pîrjol \\ Emin Cadar \\ Bogdan-Ştefan Negreanu-Pîrjol \\ "Ovidius" University of Constanţa, Faculty of Pharmacy, Campus Corp B, \\ University Alley, Nr. 1, Constanta, Romania
}

Doi:10.5901/ajis.2015.v4n1s2p253

\begin{abstract}
The red algae Ceramium rubrum, Div. Rhodophyta, Subcl. Florideophycidae, Fam. Ceramiaceae (Huds. ) grows abundantly and spontaneously in the Black Sea. Rhodophyta are the source to produce agar-agar and carrageen used to improve the chemical and physical characteristics of several industrial products and in the production of tissue culture media. The harvesting was made by the Romanian Institute for Marine Research and Development from an unpolluted area in the Black Sea. Dry algae Ceramium rubrum were analyzed in the first step in order to identify active principles which are important to human health and then by IR and UV-VIS spectrometry, Atomic absorption spectrometry for heavy metals and pesticides, and finally HPLC. The paper reports the correlated results of UV-VIS spectrometry and HPLC analysis of algae extract versus $\beta$ carotene, chlorophyll a and chlorophyll b standards. A chromatographic method was applied for optimum separation of $\beta$ carotene, chlorophyll a and chlorophyll b standards with Photodiode Array and Fluorescence Detectors. In the paper we present too, a comparative study regarding antioxidative capacity of these macrophyte algae, Ceramium rubrum, specifife for Romanian Black Sea Coast. For antioxidant capacity of algae extracts, chemiluminescence method had been used. The results confirm that could be correlated with the high level antioxidant activity of these species, which relieve the possibility to enlarge the options to use these natural vegetal resources from Black Sea Coast in different degenerative diseases therapy.
\end{abstract}

Keywords: Red algae, Ceramium rubrum, UV-VIS spectra, HPLC analysis of algae, IR spectra.

\section{Introduction}

Nowadays it is very important to reconsider the resources provided by nature for food and as a source of active principles necessary for human health. Interdisciplinary studies made on the various marine algae in the Black Sea attests that some tooth they are particularly important to human health.

Ceramium rubrum belongs the red algae group: Div. Rhodophyta, Subcl. Florideophycidae, Fam. Ceramiaceae (Huds. C. Ag. ), which includes pluricellular algae that live in an aquatic environment. It is an annual species that sometimes colonizes the rocky substrata on the medium and infra-littoral, in area exposed to waves. On the Black Sea littoral, it is encountered all along the coast, on rocks, at depths from $0.5 \mathrm{~m}$ to $4-5 \mathrm{~m}$, during the whole year, developing mainly in spring and in summer. The importance of this marine alga was revealed by recent researches, which indicate it a good quality agar producer, [1]. In nature, Ceramium rubrum produces large amounts of organic substance (vegetal biomass), which provides food for aquatic animals, phytophagus fish etc, [2]. In addition, the algae eliminate oxygen into the water, which is vital for the breathing of plants and animals, see fig. 1. Economically, marine algae can be used for various purposes, such as: in agriculture, in pharmaceutical and food industry, as they are rich in organic substances, sugars and active principles, [2]. Recent investigations pointed out that, out of the numerous red algae species, Ceramium rubrum is the only one with strong antibiotic properties on Gram+ bacteria, the testing being made on Bacillus subtilis. Probably, this happens due to the appreciable amount of sulphurous crystals in the thalle cells, which are known to have inhibitory properties on the Gram+ cells. This way, the tests showed the inhibitory properties of the alga are not efficient on Gram- bacteria, though.

Ceramium rubrum has a bushy shape, it is dark red and it is fixed on the substratum through rhizoids, $[3 \div 7]$. The 
philaments have a dichotomic ramification and the growth is realized through an initial cell, at the level of the appex, which sometimes can e hidden. Each ramification ends with two short arms, which form a small claw. The philaments are made of a single row of cells, placed head to head, so that an axial structure appears, as the ends of the cells meet at the nods. Each nod forms a variable number of cells, called periaxial, which continuously divide, leading to the formation of the cortical cells. The species is remarkable due to its polymorphism, which led to the identification of more varieties, [5, $6,7]$.

The development cycle of Ceramium rubrum is trigenetic, the first generation being represented the haploid gametophyte on which the sexual organs appear, on the superior side of the male gametophyte; the spermatocysts are small and oval, [7]. Through the apparition of new haploids, the cycle begins once again; this succession of the three generations may happen several times during one year.

The harvesting - for the detailed analysis in the laboratory, the harvesting and the preservation of the algae is needed. Macrophyte algae are harvested by hand, most of the times with a knife, in order to collect intact material. Several plants are introduced in plastic bags with a small quantity of water, the tagging of the bag with the date, the depth and the place of harvesting being compulsory.

First of all, for the algal material harvested the determination of the heavy metal and pesticides content was realized, through atomic absorption spectroscopy, revealing results lower that the limits allowed by the present legislation, $[3,4,5,7]$. The rest of the harvested algal material was divided and washed, tagged accordingly and taken for analysis to the specialized laboratories. Initially, a phytochemical study was realized, based of preliminary analyses for the identification of the active principles contained in Ceramium rubrum, $[3,4,5,7]$ This way, the existence of classes so sterols, flavonic aglicones and cumarines, triperpenic heterozides, antracenozides, reducing compounds and catehic tannins was identified.

\section{Research Methods}

Ceramium rubrum red algae from the Black Sea was dried at room temperature in darkness and fine grounded was extracted with acetone $90 \%$. The filtered extract was added into a volumetric flask with the same solvent. This stock solution was diluted with different solvents and analysed by spectrophotometer and chromatographic means.

This work reports the correlated results of UV-VIS spectrometry and HPLC analysis of algae extract versus $\beta$ carotene, chlorophyll $a$ and Chlorophyll $a$ and $b$ standards. The HPLC method was carried out using the GBC-HPLC instrumentation with the following configuration: LC 1150 Quaternary Solvent Delivery System, LC 1460 Vacuum On-Line Degasser, LC 1445 System Organiser, LC 1150 Column Oven, LC 5000 Photo Diode Array Detector (DAD with the range 190-800 nm), LC 1255 Programmable Scanning Fluorescence Detector, Win Chrom Chromatography Data Management System. UV-VIS Spectrophotometric method has been applied by use of a spectrophotometer Cintra 10e with the following performance Specifications: wavelength; accuracy $\pm 0.2 \mathrm{~nm}$; wavelength reproducibility $\pm 0.04 \mathrm{~nm}$; photometric accuracy \pm 0.002 a; photometric repeatability \pm 0.0001 a; photometric noise $<0.0001 \mathrm{a}$ rms at $1 \mathrm{a}$; photometric linearity better than $1 \%$ at 3 abs; baseline flatness $<0.002 \mathrm{a}$. Hardware Specifications are: instrument format spectrometer module with external compatible computer; photometric system double-beam, direct ratio recording system; light source tungsten-halogen lamp and deuterium lamp; light source changeover automatic source changeover at userselectable wavelength; wavelength range 190-1,200 nm. HPLC method was applied for standard and sample solutions analysis and the results are illustrated by 3D View who provides a three-dimensional view of the absorbance versus time and wavelength. The 3D View enables easy location of wavelength with significant absorbance and interferences which may otherwise have been invisible in a single wavelength plot. The Spectrum Max Plot generates a chromatogram, whereby each point is plotted at its maximum absorbance, indicating how the chromatogram will appear when the wavelength for each is optimised. Diode Array Detector allows spectra acquisition in real time for every peak detected. Overlaid spectra of the sample and standard peaks expressed by Similarity Index (SI) are used for identification of each separated component. [9]

I. To determine antioxidant capacity, well-dried algae were ground, were triturated to fine powder, then got a cold extract of each species of alga, using $20 \mathrm{mg}$ of dried plant product dissolved in $1 \mathrm{~mL}$ ethylic alcohol p. a, Merck. Extraction was performed for 24 hours and 72 hours respectively, at room temperature in amber glass bottles, sealed. Mixtures were shaken regularly and separation of extracts was done by decanting, without filtering. For each algal extract antioxidant capacity was determined using the standardized method ACL (Antioxidant capacity of lipid soluble substances), by comparison with standard substance Trolox (Vitamin $\mathrm{E}$ derivative), used for calibration curve, according to standardized method Analytik Jena [10, 11]. Exposure to 
external radiation from a $\mathrm{Hg}$ lamp lined with phosphor that provides the maximum energy at $\lambda=351 \mathrm{~nm}$, photosensitive reagent, produces free radicals in the sample for analysis, resulting a photochemical reaction. After the release of radicals, antioxidants present in sample annihilate them in a certain amount, some remaining in the sample and will combine with photosensitive reagent in the absence of external excitation source detector serves as free radicals. Following the chemical reaction that emits a photon is amplified and detected by photomultiplier. It measures the total antioxidant capacity of the device's electrical signal which is converted into concentration values.

Apparatus: Photochemiluminometer PHOTOCHEM Analytik Jena, Germany, 2008 [11].

II. IR Spectrophotometric method has been applied by use of a spectrophotometer IR 4200 Jasco. IR method allows the following configuration: obtaining Fourier Transform Infrared Spectrometer FT/IR 4200 Jasco. Field of wavelengths are 7800-350 $\mathrm{cm}^{-1}$; Working Parametersare wavelength Accuracy $\pm 0.01 \mathrm{~cm}^{-1}$, full resolution 0 . $5 \mathrm{~cm}^{-1}$ Detector DLATGS (standard); Gain switching AUTO, Corecţie ATR (Attenuated Total Reflexion). We have been analyzed by IR spectrometry dried particulates marine alga (Ceramium rubrum), calibrators and beta-carotene etaon.

\section{Results and Discussions}

I. A spectrophotometric method was applied for standard and sample solutions analysis and the results are illustrated by spectrum plot and standard curve. In order to prepare standard solution for spectrophotometric and chromatographic analysis, stock solution of trans- $\beta$-carotene in diethyl ether was diluted with different solvents. The standard used in analysis for trans $\beta$-Carotene are Provitamin A 95\%, with Formula molecular $\mathrm{C}_{40} \mathrm{H}_{56}$ and Mass molar 536,89 $\mathrm{g} / \mathrm{mol}$, soluble in n-hexane, carbon disulfide, chloroform and benzene; Slightly soluble in ether, petroleum ether and oils; very slightly soluble in ethanol, methanol, water, diluted acids and alkalis. Spectral propriety data are: $\lambda_{\max } 478$ (450) $\mathrm{nm}$.

Spectral profiles are quite specific: an absorption band in VIS with the maximum at $450 \mathrm{~nm}$ and a lower intense absorption band in UV range (250-300 nm). This spectral profile characterises the trans-isomer, while the cis one has an intense absorption band in UV and a lower one in VIS range. These specific proprieties will be confirmed next by HPLC analysis.

For the Ceramium rubrum extract the Chromatographic analysis we obtained the Spectrum Max Plot Chromatogram of standard solution at $0.5 \mathrm{mg} / \mathrm{Ml}$ (Methanol/water/ethyl acetate=18/1/1), see Fig. 2. In Fig 3 a is presented the overlaid normalized spectra Peak I Ceramium rubrum with the two peaks of chlorophyll a and in Fig. $3 \mathrm{~b}$ is present The overlaid normalized spectra Peak I Ceramium rubrum with the two peaks of $\beta$-carotene. Spectral profile of each peak and overlaid spectra with the results of chromatographic analysis standard solution of Ceramium rubrum 0. $5 \mathrm{mg} / \mathrm{mLare}$ presented in Table I. [9]. The overlaid spectrum Max Plot Chromatograms of standard solution Ceramium rubrum $0.5 \mathrm{mg} / \mathrm{mL}$ and the mixture of chlorophyll a, chlorophyll $b$ and $\beta$-carotene 25ppm each is presented in Fig. 4 .

II. For Antioxidant capacity the calibration curve were used reagent kits Analytik Jena Germany Standard: R1

(dilution solvent), R2 (buffer reagent), R3 (photosensitive reagent), R4 (reagent sized). The calibration curve was constructed by measuring a series of standard solutions containing $0.5,1.0,2.0,3.0 \mathrm{nmol}$ Trolox (suitable for $5-30 \mu \mathrm{L}$ R4), as in Fig. 5). Antioxidant capacity of sample of algae, reported at the time of extraction and sample volume used in the works, according to the ACL method quantified by comparison with standard substance Trolox, and results are expressed in nmol /sample, Trolox equivalent units, according to Table 2 and Fig. 5 [11]. Shows high Antioxidant activity, the most intense being in the case of Ceramium rubrum to 72 hours, activity which could be used in order to get more value from these species in diseases therapy on degenerative diseases.

III. IR Spectra obtained for each seaweed and marine as well as spectra of alga with the standard of carotene are shown in Figures 6 and 7 IR Spectra obtained illustrate this functional groups characteristic of beta-carotene.

\section{Conclusion}

During the work has been performed comparative studies on marine seaweed Ceramium rubrum by a number of different methods of analysis.

By spectrophotometric method in the UV-VIS and chromatographic method has highlighted existing active principles important such as chlorophyll $a$ and $b$ contents and beta-carotene.

- Existing beta carotene is confirmed by the IR spectra obtained. 
- The outcome of the tests on Ceramium rubrum show that high antioxidant activity is most intense being to 72 hours, work that could be used for purposes of capitalization of these species in the treatment of degenerative diseases.

- Ceramium rubrum is an important source for pharmaceutical industry to human health.

\section{References}

Amine EK, and Hegsted DM. (1974), Biological assessment of available iron in food products. J. Agric. Food Chem. , 22: 470-475.

Bocanegra A, Neto A, Blas B, and Sanchez-Muniz FJ. (2003), Diets containing a high percentage of Nori or Konbu algae are wellaccepted and efficiently utilised by growing rats but induce different degrees of histological changes in the liver and bowel. Food Chem. Toxicol. , 41 (11): 1473-80.

Ciulei I. , Istudor V. , Palade M. , Albulescu D. , Gârd C. E. (1995), Pharmacognostical and Fito-chemical Analysis of Plant Products , Tehnoplast Company, Bucharest, vol. I.

Istudor V. (1998), Pharmacognosy, Plant chemistry, Plant Therapy, Medical Publishing House, Bucharest, vol. I

Palade M. (1999), Pharmaceutical Botanical, Technical Publishing House, Bucharest, vol I.

Palade M. (1999), Pharmaceutical Botanica, Technical Publishing House, Bucharest, vol II.

Peterfi S. , Ionescu Al. , Treaty of the alga, (1976-1981), Vol. I-IV, Educational and pedagogical Publishing House, Bucharest.

C. Sava, Rodica SÎRBU, Albertine LEON, (2012), Hyphenated Techniques Applied for Active Principles Determination in Ceramium rubrum Algae from the Black Sea, Journal of Environmental Protection and Ecology, Vol 13, No. 1, pag. 289-299.

Popov I, Lewin G. (1999), Antioxidative Homeostasis: Characterisation by Means of Chemoluminescent Technique. In: Methods of Enzymology: Volume 300, Oxidants and Antioxidants. Part B. (437-456), Editor L. Packer, Academic Press.

Rohe M. Photochem - bioanalytical solutions. Measurement of antioxidants: Detection of the antioxidative capacity of complex samples by chemiluminescence,http: //www. mep. net. au/teachingresearch/TRL_12/TRL12_PHOTOCHEM_Info_e_10_12_04. pdf

Ticuţa Negreanu-Pîrjol, B. Negreanu-Pîrjol, R. Sîrbu, G. Paraschiv, A. Meghea, (2012), Comparative studies regarding the antioxidative activity of some therapeutic marine algae species along Romanian Black Sea Coast', Journal of Environmental Protection and Ecology, 13, No. 3A, 1744-1750,

\section{Figures And Tables}

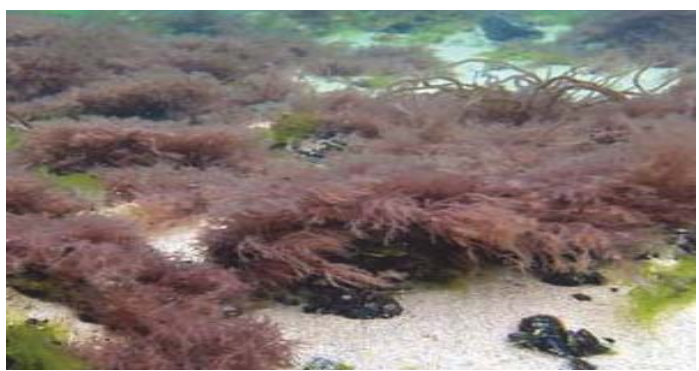

Fig. 1 Ceramium rubrum in an aquatic environment

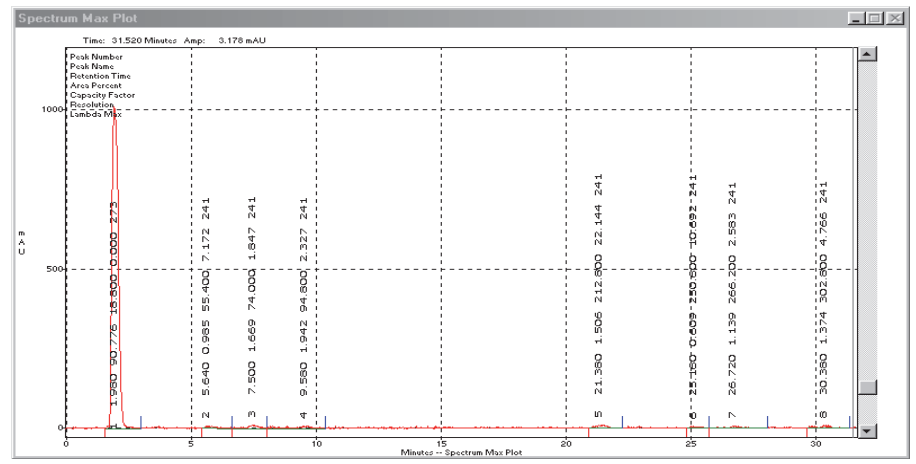

Fig. 2 The Spectrum Max Plot Chromatogram Standard solution of Ceramium rubrum 0. 5mg/ml (Methanol/water/ethyl acetate=18/1/1) 

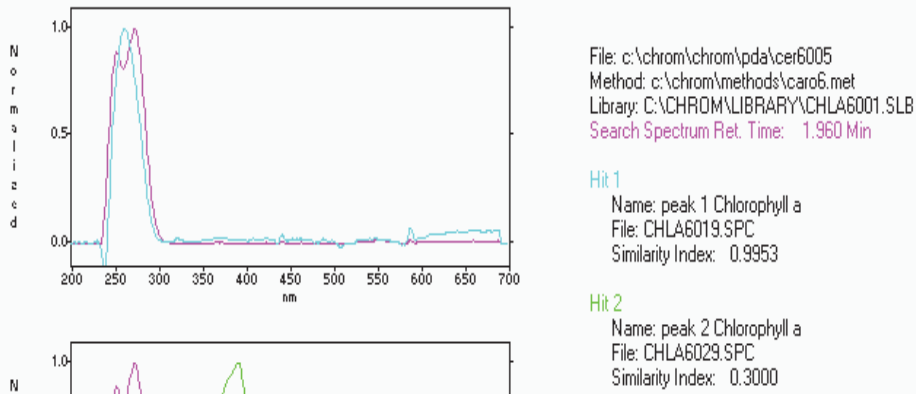

Similarity Index: 0.3000

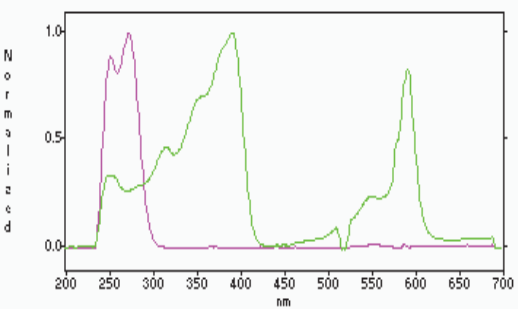

Fig. 3 a. The overlaid normalized spectra Peak I Ceramium rubrum with the two peaks of chlorophyll a

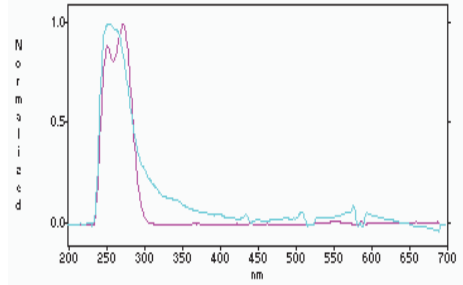

File: c: Chromichrom $y$ dalcer 6005 Method: c: ichrom methodsicaro6. met

Librayy. C:CHROMYLIBRARYYCAR06009.SLB

Search Spectrum : CER6015.SPC

Hit 1

Name: peak 1 B-caroten

File: CAR06019.SPC

Similarity Index. 0.9682

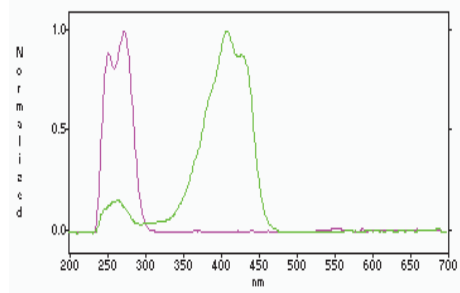

Name: peak $2 B$-caroten

File: CAR06029.SPC

Similarity Index: 0.13

Fig. 3 b. The overlaid normalized spectra Peak I Ceramium rubrum with the two peaks of $\beta$-carotene

Table I. The results of chromatographic analysis Standard solution of Ceramium rubrum $0.5 \mathrm{mg} / \mathrm{ml}$

(Methanol/water/ethyl acetate $=18 / 1 / 1$ )

\begin{tabular}{|c|c|c|c|c|c|c|}
\hline Peak No. & Peak I & Peak II & Peak III & Peak IV & Peak V & Peak VI \\
\hline$t_{R}$ (min. ) & 1.98 & 5.64 & 7.50 & 9.58 & 21.38 & 25.16 \\
\hline Aria \% & 90.776 & 0.985 & 1.669 & 1.942 & 1.506 & 0.609 \\
\hline Capacity Factor & 18,80 & 55.40 & 74 & 94.8 & 212.8 & 250.8 \\
\hline Resolution & 0 & 7.172 & 1.847 & 2.327 & 22.144 & 10.692 \\
\hline$\lambda \max (\mathrm{nm})$ & 273 & 241 & 241 & 241 & 241 & 241 \\
\hline
\end{tabular}




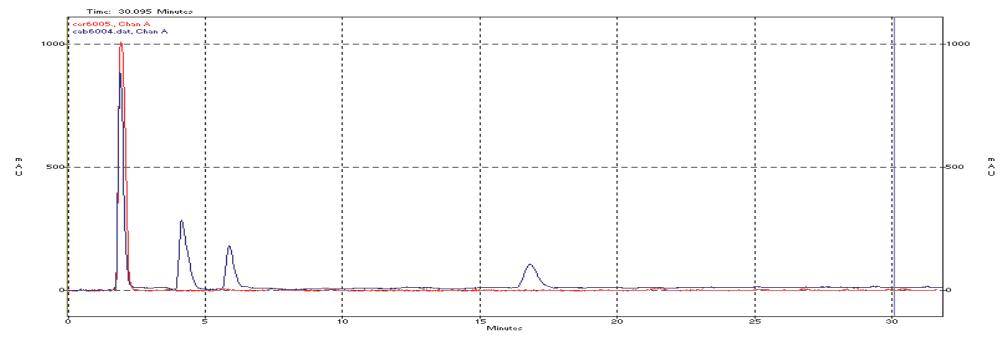

Fig. 4 Overlaid Spectrum Max Plot Chromatograms of standard solution Ceramium rubrum $0.5 \mathrm{mg} / \mathrm{mL}$ and the mixture of chlorophyll a, chlorophyll b and $\beta$-carotene 25ppm each

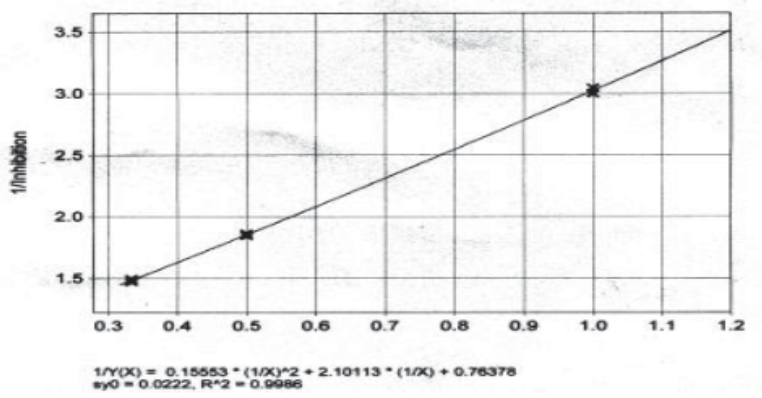

Fig. 5. Calibration curve for standard Trolox (ACL method, Analytik Jena, Germany)

Tabelul II. Antioxidant Capacity of Trolox (method ACL)

\begin{tabular}{|c|c|c|c|c|c|}
\hline $\begin{array}{c}\text { Sample } \\
\text { (Algae type) }\end{array}$ & $\begin{array}{c}\text { The extraction } \\
\text { time (hours) }\end{array}$ & $\begin{array}{c}\text { The volume of the sample } \\
\text { used }(\mu \mathrm{L})\end{array}$ & $\begin{array}{c}\text { The analysis Time } \\
(\mathrm{sec})\end{array}$ & $\begin{array}{c}\text { Trolox equivalent units } \\
\text { (nmol/volume sample) } \\
\text { (nmol/ volum sample) }\end{array}$ & $\begin{array}{c}\text { Trolox equivalent units } \\
\text { (nmol/g dry sample) } \\
\text { (nmol/g dry sample) }\end{array}$ \\
\hline $\begin{array}{c}\text { Ceramium } \\
\text { rubrum }\end{array}$ & 24 & 20 & 120 & 1,042 & 52,1 \\
\cline { 2 - 6 } & 72 & 20 & 120 & 2.83 & 141,5 \\
\hline
\end{tabular}

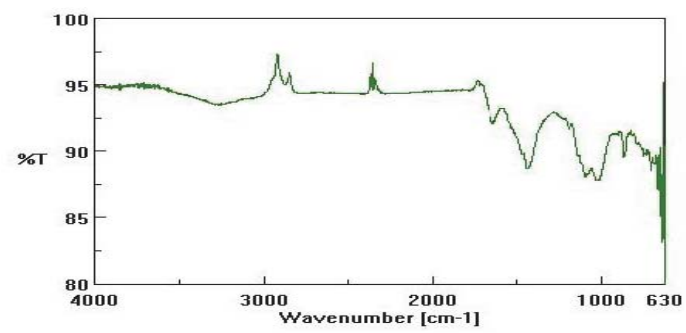

Fig. 6 IR Spectrum of sea weed Ceramium rubrum

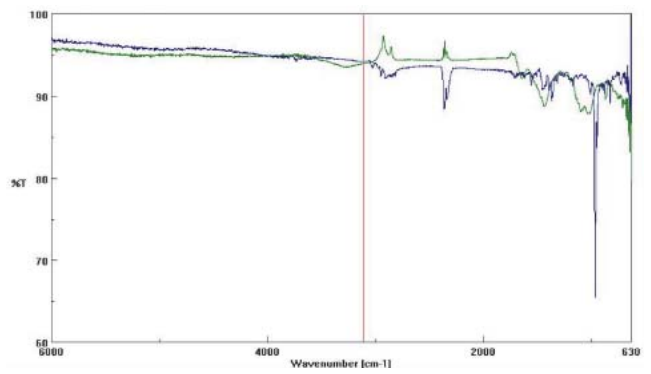

Fig. 7 IR Spectra overlapping of sea weed dry powder, in the range from $4.000-630 \mathrm{~cm}^{-1}$ Ceramium rubrum dry powder (green) and beta-carotene solid (blue), in the range from $4.000-630 \mathrm{~cm}^{-1}$ 